\title{
Exercise and NO production: relevance and implications in the cardiopulmonary system
}

\section{Alexei V. Nosarev ${ }^{1 *}$, Lyudmila V. Smagliy ${ }^{2}$, Yana Anfinogenova ${ }^{1,3}$, Sergey V. Popov ${ }^{3}$ and Leonid V. Kapilevich ${ }^{4}$}

1 Institute of Physics and Technology, National Research Tomsk Polytechnic University, Tomsk, Russia

${ }^{2}$ Department of Biophysics and Functional Diagnostics, Siberian State Medical University, Tomsk, Russia

${ }^{3}$ Research Institute for Cardiology, Federal State Budgetary Scientific Institution, Tomsk, Russia

${ }^{4}$ Faculty of Physical Education, National Research Tomsk State University, Tomsk, Russia

\section{Edited by:}

Dmitriy N. Atochin, Harvard Medical

School, USA

\section{Reviewed by:}

Nazareno Paolocci, Johns Hopkins

University, USA

Elena N. Dedkova, Rush University

Medical Center, USA

${ }^{*}$ Correspondence:

Alexei V. Nosarev, National Research

Tomsk Polytechnic University, 30

Lenina Avenue, Tomsk 634050,

Russia

e-mail: avnosarev@yandex.ru
This article reviews the existing knowledge about the effects of physical exercise on nitric oxide (NO) production in the cardiopulmonary system. The authors review the sources of $\mathrm{NO}$ in the cardiopulmonary system; involvement of three forms of NO synthases (eNOS, nNOS, and iNOS) in exercise physiology; exercise-induced modulation of $\mathrm{NO}$ and/or NOS in physiological and pathophysiological conditions in human subjects and animal models in the absence and presence of pharmacological modulators; and significance of exercise-induced NO production in health and disease. The authors suggest that physical activity significantly improves functioning of the cardiovascular system through an increase in NO bioavailability, potentiation of antioxidant defense, and decrease in the expression of reactive oxygen species-forming enzymes. Regular physical exercises are considered a useful approach to treat cardiovascular diseases. Future studies should focus on detailed identification of (i) the exercise-mediated mechanisms of NO exchange; (ii) optimal exercise approaches to improve cardiovascular function in health and disease; and (iii) physical effort thresholds.

Keywords: nitric oxide, nitric oxide synthase, exercise, cardiopulmonary system, blood vessels

\section{INTRODUCTION}

Nitric oxide (NO) is a free radical with the high reactivity and diffusion rate (Garthwaite et al., 1988; Archer, 1993; Brunori et al., 2006). Direct measurements of NO content in biological tissues are complicated due to NO binding to hemoglobin (Lundberg et al., 1994; Griffiths et al., 2003; Brunori et al., 2006). At the same time, $\mathrm{NO}$ is stable at the low concentrations ranging from 0.1 to $100 \mathrm{nM}$ (Archer, 1993; Griffiths et al., 2003). Due to this, NO, synthesized in the hollow organs, diffuses into the lumen where it can be detected in the gaseous phase (Archer, 1993). Nitric oxide, synthesized in the airways, can be detected in the exhaled air (Alving et al., 1993; Lundberg et al., 1994). Nitric oxide content in the exhaled air can characterize metabolic (Whittle, 1995) and physiological conditions of the respiratory organs (Alving et al., 1993; Barnes and Kharitonov, 1996; Dweik et al., 1998).

Nitric oxide is produced by various cells (Archer, 1993; Bauer et al., 1994, p. 62). Numerous studies suggest that NO synthesis depends on physical stimuli that modulate the activity of NO synthases (NOS) (Laughlin et al., 2001; Gielen et al., 2005; Park et al., 2012). Three isoforms of NOS were identified: neuronal (nNOS), macrophage or inducible (iNOS), and endothelial (eNOS) isoforms encoded by distinct genes (Ricciardolo, 2003; Garcia, 2011).

Available literature presents controversial data on exerciseinduced changes in eNOS expression.

There is evidence that 24-week course of swimming exercise does not change expression of eNOS protein in healthy mice
(Pellegrin et al., 2011). On other hand, swimming exercise increases eNOS expression at the protein level in mice prone to hypercholesterolemia and atherosclerosis (Pellegrin et al., 2007, 2011). Moreover, eNOS protein expression and phosphorylation is increased in porcine coronary arteries in the models of chronic coronary occlusion and stenosis (Heaps et al., 2006). Coronary artery disease (CAD) patients, subjected to bicycle ergometer exercise, have twice higher levels of eNOS protein expression and phosphorylation compared with CAD patients with sedentary lifestyle (Hambrecht et al., 2003; Gielen et al., 2010). Other data demonstrate that exercise stimulates endotheliumdependent relaxation of collateral coronary arteries and arterioles in healthy animals. This effect is associated with increases in eNOS expression at the mRNA and protein levels (Laughlin et al., 2001). Exercise effects on vascular endothelium are mediated by stepwise increase in shear stress. An increase in the shear stress is caused by elevation of cardiac output during physical exercise (Persson et al., 1993). Signaling in the endothelial surface, exposed to the vascular lumen, is triggered by deformation of glycocalyx (Reitsma et al., 2007).

Exercise does not significantly affect nNOS in spontaneously hypertensive rats (Park et al., 2012). In patients with chronic heart failure, exercise decreases the expression of cytokines and iNOS in the muscular biopsies (Kingwell, 2000; Boo and Jo, 2003). The effects of physical exercise on iNOS and nNOS are still poorly understood. Many questions on how exercise modulates the activity of NOS isoforms remain unresolved. 


\section{SOURCES OF NITRIC OXIDE IN CARDIOPULMONARY SYSTEM}

Nitric oxide is detected in the exhaled air (Alving et al., 1993; Lundberg et al., 1994). However, the sources of NO in the exhaled air have not been clearly identified. Nitric oxide can be produced by various cells present in the lungs (Spriestersbach et al., 1995) including epithelial, neural, inflammatory (macrophages, neutrophils, and mast cells) (Gaston et al., 1994), and vascular endothelial cells (Ignarro et al., 1987; Garthwaite, 2008) (Figure 1). Significant portion of the exhaled NO is produced by the endothelium of the microvessels and pulmonary blood vessels and alveolar epithelium (Kharitonov et al., 1996; Dweik et al., 1998).

Nitric oxide can be also transported to the lungs by blood flow (Gaston et al., 1994). After release of NO into the blood stream, NO binds to hemoglobin and then it is delivered to the alveoli (Lundberg et al., 1994; Green et al., 2011). Due to a high diffusion ability (diffusion coefficient is approximately $3300 \mu \mathrm{m}^{2} / \mathrm{s}$ ), NO easily diffuses into the gaseous phase of the lungs (Ricciardolo, 2003).

The exhaled NO level is lower in patients with coronary insufficiency compared with healthy individuals (Sumino et al., 1998; Clini et al., 2000). Exercise stimulates NO release from the endothelial cells (Moncada, 1997). Regular exercises improve functioning of the blood vessels and contribute to the better myocardial perfusion and contractile function in subjects with vascular diseases (Hambrecht et al., 2000, 2003; Xie et al., 2012). However, despite obvious benefits of physical training, the main exercise-mediated mechanisms involved in the improvement of the vascular function in coronary artery disease have not been clearly identified.

Nitric oxide exchange occurs in the alveoli and other parts of the airways and significantly depends on the exhaled air flow (Silkoff et al., 1997; Tsoukias et al., 1998). The latter complicates the interpretation of NO oscillations in the exhaled air in various clinical and physiological conditions (Tsoukias and George, 1998; Shin et al., 2001, 2002; Tsoukias et al., 2001).

Nitric oxide diffuses from the endothelial cells into the vascular smooth muscle cells where this molecule activates guanylate cyclase producing cyclic guanosine-3,5-monophosphate (cGMP) from GTP. cGMP is a second messenger whose important effect

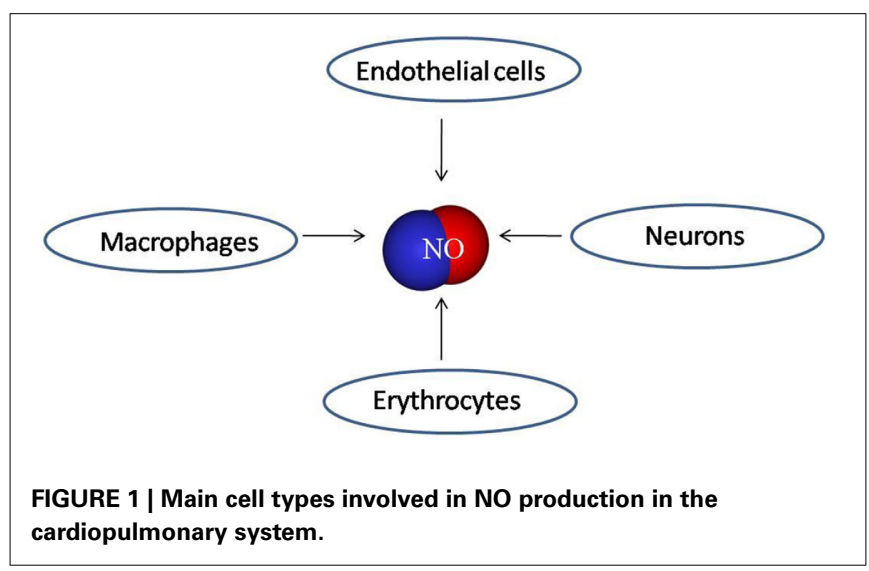

consists in the relaxation of the blood vessels (Vallance and Chan, 2001). Liao et al. (1999) studied the processes of endothelial NO diffusion into the adjacent smooth muscle cells of the porcine pulmonary blood vessels. These researchers hypothesized that hemoglobin binds almost all available NO. They also showed that erythrocytes do not disrupt NO-mediated vasodilation in the isolated microvessels when the intravascular blood flow is preserved. Therefore, the erythrocytes are not scavengers of NO in the given conditions (Liao et al., 1999). Vaughn et al. (2000) demonstrated that limited transmembrane diffusion decreases NO absorption by the erythrocytes.

At the same time, the erythrocytes contribute to the NOmediated vasodilation in the absence of intravascular blood flow. Kleinbongard et al. (2006) provided evidence of eNOS presence in human and murine erythrocytes suggesting a possibility for NO syntheses from L-arginine by the erythrocytes. Possible sources of vasoactive $\mathrm{NO}$ comprise S-nitrosohemoglobin ( $\mathrm{SNOHb}$ ) and nitrite. However, there is a lack of convincing data on how NO or its equivalents are transported to a vascular wall from either source: SNOHb or nitrites (Robinson and Lancaster, 2005). Nitric oxide can be directly released from the erythrocytes into the extracellular space or be formed outside erythrocytes from an intermediate product generated during reaction between nitrite and deoxyhemoglobin (nitrite-deoxyHb reaction) (Kim-Shapiro et al., 2005; Crawford et al., 2006). Studies demonstrated that redox-active thiols, abundant in blood plasma, can bind NO and transport it in the form of bioactive S-nitrosothiols (RSNOs) in the bloodstream (Stamler et al., 1992a). In the presence of oxygen, $\mathrm{S}$-nitroso-albumin (SNOAlb) is considered to be main product of NO binding (Stamler et al., 1992b; Marley et al., 2001). However, mechanisms of formation and release of NO from SNOAlb and other RSNOs in vivo remain completely unclear (Rassaf et al, 2002).

\section{NITRIC OXIDE SYNTHASES eNOS}

Endothelial NO synthase (eNOS) is a membrane-bound isoform of the enzyme localized in the caveolae, small invaginations of plasma membrane containing transmembrane protein caveolin (Ricciardolo, 2003; Förstermann and Sessa, 2012). eNOS is found in the lungs, trachea (Zhan et al., 2003), alveolar and bronchial epithelial cells (Pechkovsky et al, 2002), alveolar macrophages (Shaul et al., 1994; Giaid and Saleh, 1995; Aminuddin et al., 2013), vascular smooth muscle cells (Zhan et al., 2003), pulmonary endothelium, and endothelial cells of the blood vessels feeding the airways (Curzen et al., 1996; Patel et al., 1999). Immunohistochemistry approaches enabled researchers to show that eNOS is localized in the respiratory ciliated epithelium. This enzyme is present in the basal bodies of the cilia and increases the ciliary beat frequency (Zhan et al., 2003). eNOS is a calciumdependent isoform producing discrete NO quanta (Patel et al., 1999). The activity of eNOS is suppressed when the enzyme binds to caveolin in the endothelial cells. In the presence of the agonist-induced $\mathrm{Ca}^{2+}$ currents, eNOS binds to calmodulin and dissociates from caveolin. Synthesis of NO by the complex of eNOS-calmodulin continues until the $\mathrm{Ca}^{2+}$ currents have 
decreased and the inhibitory eNOS-caveolin complex has formed (Michel and Feron, 1997). Nitric oxide, synthesized by eNOS, is involved in the regulation of arterial blood pressure and airway lumen diameter (Whittle, 1995).

\section{nNOS}

Neuronal NO synthase (nNOS) is a soluble cytosolic isoform of NO synthase (NOS) (Ricciardolo, 2003). nNOS is found in different cells present in the lungs including neuronal (Tzao et al., 2000; Lührs et al., 2002), epithelial (Belvisi et al., 1995), and endothelial cells (Shaul et al., 1994; Aminuddin et al., 2013). The presence of nNOS in the nerve fibers is demonstrated by immunohistochemistry and NADPH-diaphoresis histochemistry (Fischer et al., 2002).

In the peripheral blood vessels of the lungs, smooth muscles are innervated by the $\mathrm{NO}$-ergic nerves, i.e., the nerves that express nNOS and therefore generate and release NO. Nitric oxide, produced by nNOS in the NO-ergic nerves, can be considered as a neurotransmitter stimulating $\mathrm{NO}$-sensitive guanylate cyclase in different types of smooth muscle cells of the blood vessels and airways (Ward et al., 1995; Patel et al., 1999; Förstermann and Sessa, 2012). Similarly to eNOS, nNOS requires calcium ions to produce NO (Whittle, 1995).

\section{iNOS}

According to current knowledge, inducible NO synthase (iNOS) is present in the macrophages and other cells present in the lungs (Fischer et al., 2002). In particular, iNOS is expressed in the epithelial cells of human airways (Guo et al., 1995; Pechkovsky et al, 2002), type II alveolar epithelium, pulmonary endothelium (Aminuddin et al., 2013), lung fibroblasts (Romanska et al., 2002), bronchial and vascular smooth muscle cells (Xue and Johns, 1996), must cells (Gilchrist et al., 2002), endothelial cells (Ermert et al., 2002), chondrocytes, and neutrophils (Blackford et al., 1994). Similarly to nNOS, iNOS is a soluble cytosolic protein (Ricciardolo, 2003).

Unlike eNOS and nNOS, iNOS is $\mathrm{Ca}^{2+}$-independent enzyme that generates NO more abundantly (nanomolar and micromolar concentrations) compared with other NOS isoforms and maintains NO production for hours and days (Ricciardolo, 2003). A large number of studies (Pautz et al., 2010; Cortese-Krott et al., 2014) demonstrated that iNOS can produce nitric oxide in micromolar concentrations. These high levels of iNOS-derived nitric oxide have been shown to be involved in pathological conditions, e.g., the blood pressure fall in septic shock as well as in the pathogenesis of chronic inflammatory diseases, including atherosclerosis. Inducible NOS is controlled at the pretranslational level. iNOS upregulation is triggered by the proinflammatory cytokines: tumor necrosis factor (TNF)- $\alpha$, interferon (INF)- $\gamma$, and interleukin (IL)-1 $\beta$ (Morris and Billiar, 1994). Increase in the production of NO by iNOS is observed in response to the endotoxins (Michel and Feron, 1997). Activation of iNOS is triggered by the pathophysiological events associated with inflammation (Whyte and Laughlin, 2010). Cytokine-induced stimulation activates iNOS in different cell types (Ito et al., 2013) except human bronchial smooth muscle cells (Förstermann et al., 1994; Patel et al., 1999; Maarsingh et al., 2009). High expression of iNOS in the presence of inflammation is documented in the murine bronchial smooth muscle cells (Kane et al., 1994; Maarsingh et al., 2009).

\section{EXERCISE-INDUCED MODULATION OF NO PRODUCTION}

The extensive evidence points to the fact that exercise stimulates NO release. This explains why regular physical activity can slow down, suppress, or even reverse cardiovascular diseases (Alving et al., 1993; Carrizzo et al., 2013). However, literature also presents contradicting data suggesting that both NOS activity and NO production decrease in response to exercise (Miyauchi et al., 2003).

\section{EXERCISE-INDUCED MODULATION OF NO PRODUCTION IN ANIMAL STUDIES}

Exercise modulates both the activity of eNOS and the expression of this enzyme at the mRNA and protein levels in the cells of aorta, heart, lung, and vena cava (Dao et al., 2011).

In vivo studies demonstrated the presence of exercise-mediated activation of $\mathrm{Ca}^{2+}$-dependent eNOS in murine lungs, aorta, and atria. Moreover, eNOS expression increases in the cells of cardiopulmonary system in laboratory animals (Tatchum-Talom et al., 2000). Physiological adaptation to swimming exercise potentiates acetylcholine-induced relaxation of blood vessels and nNOS activation in the endothelial cells of the lungs, atria, and aorta (Tatchum-Talom et al., 2000).

Many studies demonstrated that NO synthesis in the endothelial cells largely depends on the level of the individual physical activity. For example, exercise-induced relaxation of the collateral coronary arteries is associated with the increased expression of eNOS mRNA and protein in healthy animals (Sessa et al., 1994; Laughlin et al., 2001). Expression of eNOS mRNA is significantly higher in the lungs of animals subjected to physical exercise compared with resting animals. Western blot analysis demonstrated that eNOS is downregulated whereas iNOS is unchanged in the pulmonary tissue after exercise (Miyauchi et al., 2003). In porcine coronary arteries, the levels of both unphosphorylated and phosphorylated (Ser1179) eNOS increase after exercise in the model of chronic coronary occlusion/stenosis (Heaps et al., 2006). Hambrecht and coworkers demonstrated healing effects of exercise in patients with coronary artery disease. The study suggested that these beneficial effects are mediated through an increase in iNOS phosphorylation by protein kinase Akt (protein kinase B) (Hambrecht et al., 2003). Akt-kinase and AMP-activated protein kinase play a pivotal role in the phosphorylation of arterial eNOS at Ser1177 residue during running exercise (Zhang et al., 2009). Moien-Afshari et al. (2008) showed that seven-week physical training increases the level of eNOS phosphorylation in the cells derived from aorta of wild-type and diabetic rats (Patel et al., 1999). The increase in eNOS phosphorylation is considered to be an important molecular mechanism of adaptation to physical exercises (Shaul et al., 1994).

Data demonstrated that physical exercise decreases expression of iNOS at the mRNA and protein levels in the cells of blood vessels (Gielen et al., 2005). There is evidence that an increase in iNOS expression can occur under the influence of Toll-like receptors type 4 (TLR-4) through the activation of 
nuclear transcription factor-kappa B (NF-kB). The levels of TLR4 and iNOS mRNAs increase after physical activity. Therefore, TLR-4 activation, mediated by NF-kB-dependent pathway, triggers the mechanisms of NO synthesis that can negatively affect myocardium in case of strenuous physical activity (CristiMontero et al., 2012).

\section{IMPACT OF PHARMACOLOGICAL MODULATION DURING PHYSICAL EFFORTS IN TRAINING}

Angelis with coworkers studied rats with normal blood pressure and hypertension caused by NOS blockage with N(omega)nitro-L-arginine methyl ester. The study showed that exercise increases arterial blood pressure, heart rate, and cardiac output in normotensive rats. In hypertensive animals, physical exercise increases heart rate without affecting cardiac output, arterial blood pressure, and blood flow and is associated with a significant increase in arteriovenous oxygen gradient. Therefore, hypertension, associated with abnormal NO production, induces different cardiovascular adjustments to exercise (De Angelis et al., 2006).

In ovine pulmonary circulation system, vascular tone increases in response to $\alpha$ - and $\beta$-adrenergic stimulation present in exercise. The increase in NO production contributes to a significant decrease in $\alpha$-adrenergic constriction of the pulmonary arteries during physical activity and dilates pulmonary blood vessels at rest (Kane et al., 1994). Experiments on sheep, subjected to physical exercise, demonstrated that intravenous infusion of Larginine, a substrate for NO synthesis, reverses the effect of NO-synthase inhibition without affecting the tone of the pulmonary blood vessels (Koizumi et al., 1994). Similar responses to moderate/heavy exercise can be found in humans with preserved endothelial function (Green et al., 2011).

Exercise affects endothelium-independent relaxation in response to NO donor sodium nitroprusside. Therefore, NOstimulated cGMP/PKG cascade in the smooth muscle cells of arterioles is not disrupted by physical exercise (Thengchaisri et al., 2007).

\section{HUMAN STUDIES}

A vast pool of data suggests that exercise modulates NO synthesis in various tissues through altering NOS activity (Laughlin et al., 2001; Boo and Jo, 2003; Gielen et al., 2005; Park et al., 2012). Nitric oxide clearly affects physiological functions in exercise (Sheel et al., 1999). However, phenomenology and mechanisms of the exercise-induced effects on NO production remain largely unclear. Biological sample acquisition from humans subjected to physical exercise is challenging. In human studies, the changes in NO production are predominantly evaluated based on the measurements of NO content in the exhaled air.

Changes in NO content in the exhaled air have been demonstrated in many studies. Majority of the studies revealed a decrease in NO content in the exhaled air after physical exercise (Maroun et al., 1995, p. 102). However, available literature also presents data suggesting that physical training is associated with an increase in NO content in the exhaled air (Bauer et al., 1994; Bonsignore et al., 2001) or its invariance (Iwamoto et al., 1994; Maroun et al., 1995). This controversy is unsurprising due to the complexity of NO exchange and multisystemic nature of the physiological responses to physical exercise.

The concentration of $\mathrm{NO}$ in the exhaled air significantly decreases after exercise (Kippelen et al., 2002; Mantione et al., 2007). After training workout, NO levels in the exhaled air are significantly lower in the subjects who continue moving compared with those fully resting. These data suggest that NO content variations in the exhaled air depend on the individual levels of physical activity (Mantione et al., 2007).

Data show a small decrease in NO content in the exhaled air 3 min after exercise (St Croix et al., 1999). Measurements of NO in trained athletes before and after workout demonstrate a decrease in NO content in the exhaled air after exercise (Verges et al., 2005, 2006). At the same time, strenuous exercise potentiates NO diffusion from the pulmonary tissue to the gaseous phase (Shin et al., 2003).

Data suggest that NO synthesis in the pulmonary tissue depends on the oxygen content (Mantione et al., 2007). Decrease in NO concentration in the exhaled air suggests high NO utilization. Partial pressure decrease after physical exercise attenuates NOS activity in the NO-producing cells (Mantione et al., 2007). In humans, the exhaled NO level directly correlates with the exhaled oxygen level particularly in case of hypoxia (Verges et al., 2005). Moreover, there is a direct correlation between iNOS activity and oxygen concentration (Dweik et al., 1998). Reactive oxygen species play an important role in the pathophysiological processes in cardiovascular system (Faraci, 2006). It is interesting that $\mathrm{H}_{2} \mathrm{O}_{2}$ potentially mediates vascular adaptation during exercise (Sindler et al., 2009). Moreover, NO production by the capillary endothelium controls oxygen consumption by the mitochondria through chemical interaction between $\mathrm{NO}$ and iron-sulfur centers of the enzymes (Shen et al., 1995). Aerobic exercise increases eNOS expression at mRNA and protein levels in patients with CAD (Hambrecht et al., 2003). Similar results were obtained in pulmonary arteries from pigs (Johnson et al., 2001) and spontaneously hypertensive rats (Ma and Zhao, 2014). Jones and colleagues report that NOS inhibition by LNAME significantly increases the absorption rate of pulmonary oxygen $\left(\mathrm{VO}_{2}\right)$ in humans subjected to moderate cyclic exercise. In the beginning of moderate exercise, the internal inertia of oxidative metabolism can lead to the competitive inhibition of $\mathrm{VO}_{2}$ by $\mathrm{NO}$ in the mitochondrial cytochrome $\mathrm{c}$ oxidase. However, understanding of the detailed mechanisms of how LNAME affects $\mathrm{VO}_{2}$ kinetics requires further studies (Jones et al., 2003).

Six-month exercise training reduces arterial pressure and is associated with an increase in nitrite/nitrate oxide contents in older women (Zaros et al., 2009). At the same time, when present in the blood stream, NO binds to hemoglobin that carries and metabolizes this molecule (Kosaka, 1999; Liao et al., 1999; Veeramachaneni et al., 1999; Gladwin et al., 2000; TaylorRobinson, 2000). Progression of NO-hem complex formation in vivo is a rapidly reversible process (Gladwin et al., 2000; TaylorRobinson, 2000). In the presence of low blood oxygenation, hemoglobin releases NO due to lower affinity to this molecule particularly in the venous blood (Kosaka, 1999; Taylor-Robinson, 2000). 


\section{MECHANISMS UNDERLYING EXERCISE-INDUCED NO PRODUCTION}

In the presence of physical exercise, physical and chemical stimuli control NO production. In the endothelial cells, exercise stimulates NO synthesis through chemical mechanisms (Garcia, 2011). Chemical mechanisms involve interaction of endogenous/exogenous agonists (acetylcholine, bradykinin, and ATP) with the specific receptors on the endothelial cells. Evidence suggests that physical exercise stimulates release of these molecules. In exercise, the efferent nerve neuromuscular junctions are the physiological source of acetylcholine (Kingwell, 2000). Erythrocytes have been shown to release ATP in response both to low erythrocyte hemoglobin oxygen saturation $\left(\mathrm{SO}_{2}\right)$ (Dietrich et al., 2000; Ellsworth et al., 2009) and to increased shear stress on the erythrocyte membrane (Wan et al., 2008). Interstitial bradykinin content is increased in the muscle contraction during strenuous exercise (Langberg et al., 2002). In the circumflex coronary artery, physical activity moderately increases the adenosine-stimulated NO production. A NOS inhibitor, L-NAME, moderately attenuates arteriolar dilatation in response to NOS activation in animals subjected to exercise (Thengchaisri et al., 2007).

According to data of Calvert and coworkers, $\beta 3$-adrenoceptors play critical role in the regulation of phosphorylation (activation) of eNOS and NO generation in response to exercise. Trained mice have the increased NO production and levels of nitrates and nitrosothiols in the heart (Calvert et al., 2011).

Physical impact on the vascular wall stimulates NO release in the blood vessels (Persson et al., 1993). The hypothetical physical stimulus affecting NO synthesis is the shear stress i.e., the friction force between fluid layers flowing at different speed. Human and animal studies suggest that exercise-induced cardiac output elevation contributes to the increased shear stress in the blood vessels (Persson et al., 1993). The increased exercise-induced shear stress, in turn, stimulates the release of vasorelaxation factor (NO) and augments eNOS and nNOS expression (Whyte and Laughlin, 2010).

Mechanisms of the shear stress-induced NO synthesis are not completely understood. It is known that the endothelial cells express mechanoreceptors directly activating G-proteins, ion channels, and enzymes such as protein kinases and phosphatases generating second messengers (cGMP) (Zhan et al., 2003; Gielen et al., 2010). Blood flow delivers shear force to the vascular wall, causes deformation of the endothelial cells, and activates NOcGMP-dependent signaling system (Barnes and Belvisi, 1993) (Figure 2). Vasodilation, triggered by shear stress, in the pulmonary blood vessels is less understood compared with that in the peripheral circulation. Pulmonary vascular reactions, associated with the changes in the exhaled NO content, remain under discussion (Sheel et al., 1999).

Shear stress stimulates the endothelium-dependent production of reactive oxygen species (ROS) that plays an important role in the cardiovascular system. Indeed, superoxide and hydrogen peroxide $\left(\mathrm{H}_{2} \mathrm{O}_{2}\right)$ at low concentrations function as signaling molecules (Drouin et al., 2007; Larsen et al., 2008; Drouin and Thorin, 2009). Activation of eNOS can be caused by these ROS (Laurindo et al., 1994). Shear stress-induced NO production is

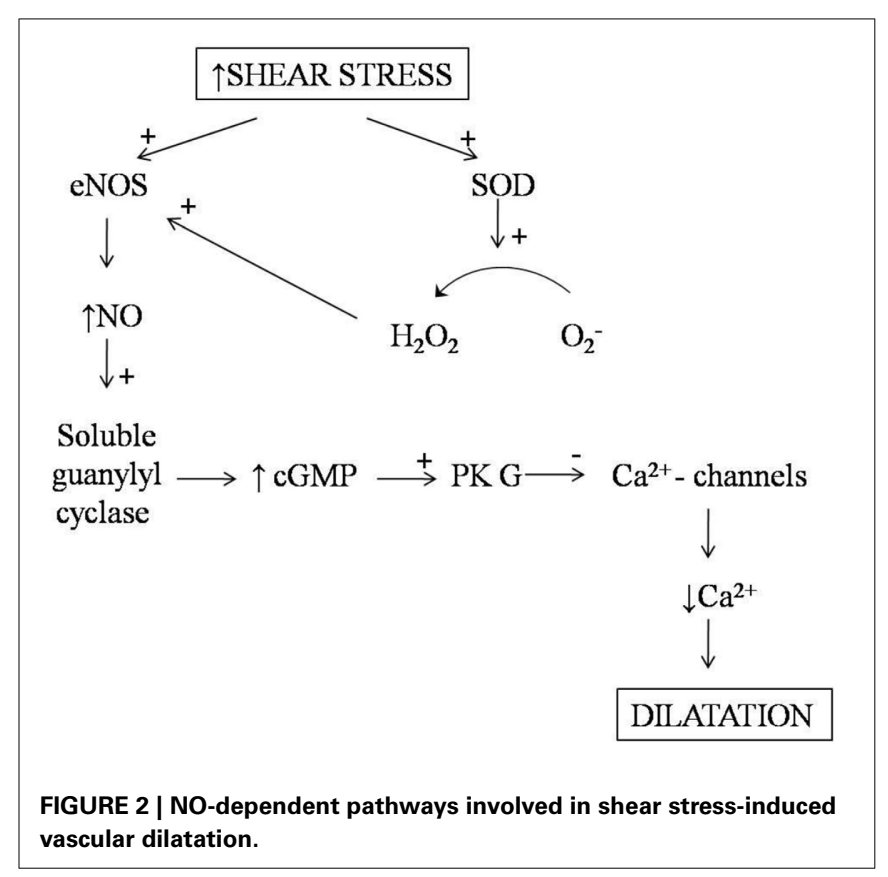

accompanied by the expression of extracellular superoxide dismutase (SOD) catalyzing the rapid dismutation of superoxide into hydrogen peroxide and molecular oxygen (Gielen et al., 2010). Hydrogen peroxide then diffuses through the vascular wall and increases eNOS expression and activity (Drummond et al., 2000; Cai et al., 2001). Therefore, increased SOD1 and SOD3 expression potentiates the exercise-induced eNOS expression through hydrogen peroxide. On the other hand, eNOS expression is not elevated in catalase transgenic mice (Rush et al., 2003). Moreover, NO can directly interact with the mitochondrial ROS generated by $\mathrm{NAD}(\mathrm{P}) \mathrm{H}$ oxidase $(\mathrm{NOX})$ and xanthine-oxidase $(\mathrm{XO})$ (Gliemann et al., 2014).

\section{SIGNIFICANCE}

Evidence suggests that physical activity alters NO production in diseases. Nitric oxide protects pulmonary tissues in asthmatic patients during exercise. A bronchoprotective role of NO was initially demonstrated by the study with an inhalation of NOS inhibitor, NG-Methyl-L-arginine (Suman and Beck, 2002). In the pulmonary rehabilitation of patients with moderate chronic obstructive pulmonary disease, improved exercise tolerance can be attributed to an increase in the exhaled NO concentration. Exhaled NO content can represent a useful pathophysiological marker of adaptation to training in these patients (Clini et al., 2001).

Exercise protects the endothelium continuity through the increase in NO production (Xie et al., 2012). When individuals with preserved endothelial function are subjected to moderate/heavy exercise, L-arginine does not affect pulmonary vascular tone, but reverses the effects of NO-synthase inhibition (Green et al., 2011). Physical exercise structurally and functionally benefits the blood vessels and, in particularly, vascular endothelium both in healthy subjects and individuals with abnormal NOinduced vasorelaxation (Green et al., 2004). Exercise efficacy 
depends on training amount and effort/intensity. Short exercise rapidly increases biological activity of NO (Wei Xie et al., 2012) whereas prolonged training causes NO-dependent arterial remodeling and normalization of shear stress response (Maiorana et al., 2003). These, in turn, eliminate need for continuous functioning of NO-dependent systems to maintain vasodilation.

Physical activity significantly improves functioning of the cardiovascular system through the increase in NO bioavailability, potentiation of antioxidant defense, and decrease in the expression of ROS-forming enzymes (Rush et al., 2005). Regular exercise is a useful tool to fight cardiovascular diseases. Future studies should focus on identification of exercise approaches optimal for achieving the increased NO bioavailability and improved cardiovascular function (Gliemann et al., 2014).

\section{CONCLUSIONS}

Existing data on exercise-mediated mechanisms of NO production in the cardiopulmonary system remain controversial. Nitric oxide is produced by various cell types including those present in the blood vessels. All these cells are potential sources of NO in the exhaled air. According to a vast pool of data, exercise controls NO synthesis through modulation of NOS activity (Laughlin et al., 2001; Boo and Jo, 2003; Gielen et al., 2005; Park et al., 2012). In response to exercise, the exhaled NO content increases, decreases, or remains unchanged depending on the presence of local factors. These factors comprise the levels NOS expression and activity, severity of oxidative stress, NO binding to antioxidant molecules hemoglobin and glutathione (Ricciardolo, 2003), and individual pattern of physical activity (Sessa et al., 1994; Laughlin et al., 2001). Evidence suggests the possible existence of the exercise amount/effort thresholds pivotal for the regulation of NO production. However, precise identification of these physical effort thresholds requires further studies (Garcia, 2011).

\section{REFERENCES}

Alving, K., Weitzberg, E., and Lundberg, J. M. (1993). Increased amount of nitric oxide in exhaled air of asthmatics. Eur. Respir. J. 6, 1368-1370.

Aminuddin, F., Hackett, T. L., Stefanowicz, D., Saferali, A., Paré, P. D., Gulsvik, A., et al. (2013). Nitric oxide synthase polymorphisms, gene expression and lung function in chronic obstructive pulmonary disease. BMC Pulm. Med. 13:64. doi: 10.1186/1471-2466-13-64

Archer, S. (1993). Measurement of nitric oxide in biological models. FASEB J. 7, 349-360.

Barnes, P. J., and Belvisi, M. G. (1993). Nitric oxide and lung disease. Thorax 48, 1034-1043. doi: 10.1136/thx.48.10.1034

Barnes, P. J., and Kharitonov, S. A. (1996). Exhaled nitric oxide: a new lung function test. Thorax 51, 233-237. doi: 10.1136/thx.51.3.233

Bauer, J. A., Wald, J. A., Doran, S., and Soda, D. (1994). Endogenous nitric oxide in expired air: effects of acute exercise in humans. Life Sci. 55, 1903-1909. doi: 10.1016/0024-3205(94)00522-2

Belvisi, M. G., Ward, J. K., Mitchell, J. A., and Barnes, P. J. (1995). Nitric oxide as a neurotransmitter in human airways. Arch. Int. Pharmacodyn. Ther. 329, 97-110.

Blackford, J. A. Jr., Antonini, J. M., Castranova, V., and Dey, R. D. (1994). Intratracheal instillation of silica up-regulates inducible nitric oxide synthase gene expression and increases nitric oxide production in alveolar macrophages and neutrophils. Am. J. Respir. Cell. Mol. Biol. 11, 426-431. doi: 10.1165/ajrcmb.11.4.7522485

Bonsignore, M. R., Morici, G., Riccobono, L., Insalaco, G., Bonanno, A., Profita, M., et al. (2001). Airway inflammation in nonasthmatic amateur runners. Am. J. Physiol. Lung Cell Mol. Physiol. 281, L668-L676. Available online at: http://ajplung.physiology.org/content/281/3/L668.full-text.pdf+html
Boo, Y. C., and Jo, H. (2003). Flow-dependent regulation of endothelial nitric oxide synthase: role of protein kinases. Am. J. Physiol. Cell Physiol. 285, C499-C508. doi: 10.1152/ajpcell.00122.2003

Brunori, M., Forte, E., Arese, M., Mastronicola, D., Giuffrè, A., and Sarti, P. (2006). Nitric oxide and the respiratory enzyme. Biochim. Biophys. Acta 1757, 1144-54. doi: 10.1016/j.bbabio.2006.05.011

Cai, H., Davis, M. E., Drummond, G. R., and Harrison, D. G. (2001). Induction of endothelial NO synthase by hydrogen peroxide via a $\mathrm{Ca}^{2+} /$ calmodulindependent protein kinase II/janus kinase 2-dependent pathway. Arterioscler. Thromb. Vasc. Biol. 21, 1571-1576. doi: 10.1161/hq1001.097028

Calvert, J. W., Condit, M. E., Aragón, J. P., Nicholson, C. K., Moody, B. F., Hood, R. L., et al. (2011). Exercise protects against myocardial ischemia-reperfusion injury via stimulation of $\beta(3)$-adrenergic receptors and increased nitric oxide signaling: role of nitrite and nitrosothiols. Circ. Res. 108, 1448-1458. doi: 10.1161/CIRCRESAHA.111.241117

Carrizzo, A., Puca, A., Damato, A., Marino, M., Franco, E., Pompeo, F., et al. (2013). Resveratrol improves vascular function in patients with hypertension and dyslipidemia by modulating NO metabolism. Hypertension. 62, 359-366. doi: 10.1161/HYPERTENSIONAHA.111.01009

Clini, E., Bianchi, L., Foglio, K., Porta, R., Vitacca, M., and Ambrosino, N. (2001). Effect of pulmonary rehabilitation on exhaled nitric oxide in patients with chronic obstructive pulmonary disease. Thorax 56, 519-523. doi: 10.1136/thorax.56.7.519

Clini, E., Volterrani, M., Pagani, M., Bianchi, L., Porta, R., Gile', L. S., et al. (2000). Endogenous nitric oxide in patients with chronic heart failure (CHF): relation to functional impairment and nitrate-containing therapies. Int. J. Cardiol. 73, 123-130. discussion: 131-134. doi: 10.1016/S0167-5273(00) 00211-4

Cortese-Krott, M. M., Kulakov, L., Opländer, C., Kolb-Bachofen, V., Kröncke, K. D., and Suschek, C. V. (2014). Zinc regulates iNOS-derived nitric oxide formation in endothelial cells. Redox Biol. 16, 945-954. doi: 10.1016/j.redox.2014. 06.011

Crawford, J. H., Isbell, T. S., Huang, Z., Shiva, S., Chacko, B. K., Schechter, A. N., et al. (2006). Hypoxia, red blood cells, and nitrite regulate NO-dependent hypoxic. Blood 107, 566-574. doi: 10.1182/blood-2005-07-2668

Cristi-Montero, C., Sánchez-Collado, P., Veneroso, C., Cuevas, M. J., and GonzálezGallego, J. (2012). Effect of an acute exercise bout on Toll-like receptor 4 and inflammatory mechanisms in rat heart. Rev. Med. Chil. 140, 1282-1288. doi: 10.4067/S0034-98872012001000007

Curzen, N. P., Jourdan, K. B., and Mitchell, J. A. (1996). Endothelial modification of pulmonary vascular tone. J. Intensive Care Med. 22, 596-607. doi: 10.1007/BF01708105

Dao, V. T., Floeren, M., Kumpf, S., Both, C., Peter, B., Balz, V., et al. (2011). Catalase activity prevents exercise-induced up-regulation of vasoprotective proteins in venous tissue. J. Cell Mol. Med. 15, 2326-2334. doi: 10.1111/j.15824934.2010.01227.x

De Angelis, K., Ogawa, T., Sanches, I. C., Rigatto, K. V., Krieger, E. M., and Irigoyen, M. C. (2006). Impairment on cardiac output and blood flow adjustments to exercise in L-NAME-induced hypertensive rats. J. Cardiovasc. Pharmacol. 47, 371-376. doi: 10.1097/01.fjc.0000210068.70076.e2

Dietrich, H. H., Ellsworth, M. L., Sprague, R. S., and Dacey, R. G. Jr. (2000). Red blood cell regulation of microvascular tone through adenosine triphosphate. Am. J. Physiol. Heart. Circ. Physiol. 278, H1294-H1298. Available online at: http://ajpheart.physiology.org/content/278/4/H1294.long

Drouin, A., and Thorin, E. (2009). Flow-induced dilation is mediated by Aktdependent activation of endothelial nitric oxide synthase-derived hydrogen peroxide in mouse cerebral arteries. Stroke 40, 1827-1833. doi: 10.1161/STROKEAHA.108.536805

Drouin, A., Thorin-Trescases, N., Hamel, E., Falck, J. R., and Thorin, E. (2007). Endothelial nitric oxide synthase activation leads to dilatory $\mathrm{H} 2 \mathrm{O} 2$ production in mouse cerebral arteries. Cardiovasc. Res. 73, 73-81. doi: 10.1016/j.cardiores.2006.10.005

Drummond, G. R., Cai, H., Davis, M. E., Ramasamy, S., and Harrison, D. G. (2000). Transcriptional and posttranscriptional regulation of endothelial nitric oxide synthase expression by hydrogen peroxide. Circ. Res. 86, 347-354. doi: 10.1161/01.RES.86.3.347

Dweik, R. A., Laskowski, D., Abu-Soud, H. M., Kaneko, F., Hutte, R., Stuehr, D. J., et al. (1998). Nitric oxide synthesis in the lung. Regulation by oxygen through a kinetic mechanism. J. Clin. Invest. 101, 660-666. doi: 10.1172/JCI1378 
Ellsworth, M. L., Ellis, C. G., Goldman, D., Stephenson, A. H., Dietrich, H. H., and Sprague, R. S. (2009). Erythrocytes: oxygen sensors and modulators of vascular tone. Physiology (Bethesda) 24, 107-116. doi: 10.1152/physiol.00038.2008

Ermert, M., Ruppert, C., Günther, A., Duncker, H. R., Seeger, W., and Ermert, L. (2002). Cell-specific nitric oxide synthase-isoenzyme expression and regulation in response to endotoxin in intact rat lungs. Lab. Invest. 82, 425-441. doi: 10.1038/labinvest.3780436

Faraci, F. M. (2006). Reactive oxygen species: influence on cerebral vascular tone. J. Appl. Physiol. (1985) 100, 739-743. doi: 10.1152/japplphysiol.01044.2005

Fischer, A., Folkerts, G., Geppetti, P., and Groneberg, D. A. (2002). Mediators of asthma: nitric oxide. Pulm. Pharmacol. Ther. 15, 73-81. doi: 10.1006/pupt.2001.0332

Förstermann, U., Closs, E. I., Pollock, J. S., Nakane, M., Schwarz, P., Gath, I., et al. (1994). Nitric oxide synthase isozymes. Characterization, purification, molecular cloning, and functions. Hypertension 23(6 Pt 2), 1121-1131. doi: 10.1161/01.HYP.23.6.1121

Förstermann, U., and Sessa, W. C. (2012). Nitric oxide synthases: regulation and function. Eur. Heart. J. 33, 829-837, 837a-837d. doi: 10.1093/eurheartj/ehr304

Garcia, R. B. (2011). The Effects of Nitric Oxide Donors on Performance in Humans. The doctoral thesis, Barcelona.

Garthwaite, J. (2008). Concepts of neural nitric oxide-mediated transmission. Eur. J. Neurosci. 27, 2783-2802. doi: 10.1111/j.1460-9568.2008.06285.x

Garthwaite, J., Charles, S. L., and Chess-Williams, R. (1988). Endothelium-derived relaxing factor release on activation of NMDA receptors suggests role as intercellular messenger in the brain. Nature 336, 385-388. doi: 10.1038/336 $385 \mathrm{a} 0$

Gaston, B., Drazen, J. M., Loscalzo, J., and Stamler, J. S. (1994). The biology of nitrogen oxides in the airways. Am. J. Respir. Crit. Care. Med. 149(2 Pt 1), 538-551. doi: 10.1164/ajrccm.149.2.7508323

Giaid, A., and Saleh, D. (1995). Reduced expression of endothelial nitric oxide synthase in the lungs of patients with pulmonary hypertension. N. Engl. J. Med. 333, 214-221. doi: 10.1056/NEJM199507273330403

Gielen, S., Adams, V., Linke, A., Erbs, S., Möbius-Winkler, S., Schubert, A., et al. (2005). Exercise training in chronic heart failure: correlation between reduced local inflammation and improved oxidative capacity in the skeletal muscle. Eur. J. Cardiovasc. Prev. Rehabil. 12, 393-400. doi: 10.1097/01.hjr.0000174824.94892.43

Gielen, S., Schuler, G., and Adams, V. (2010). Cardiovascular effects of exercise training: molecular mechanisms. Circulation 122, 1221-1238. doi: 10.1161/CIRCULATIONAHA.110.939959

Gilchrist, M., Savoie, M., Nohara, O., Wills, F. L., Wallace, J. L., and Befus, A. D. (2002). Nitric oxide synthase and nitric oxide production in in vivo-derived mast cells. J. Leukoc. Biol. 71, 618-624. Available online at: http://www.jleukbio.org/content/71/4/618.long

Gladwin, M. T., Ognibene, F. P., Pannell, L. K., Nichols, J. S., Pease-Fye, M. E., Shelhamer, J. H., et al. (2000). Relative role of heme nitrosylation and beta-cysteine 93 nitrosation in the transport and metabolism of nitric oxide by hemoglobin in the human circulation. Proc. Natl. Acad. Sci. U.S.A. 97, 9943-9948. doi: 10.1073/pnas.180155397

Gliemann L., Nyberg, M., and Hellsten, Y. (2014). Nitric oxide and reactive oxygen species in limb vascular function: what is the effect of physical activity? Free Radic. Res. 48, 71-83. doi: 10.3109/10715762.2013.835045

Green, D. J., Maiorana, A., O’Driscoll, G., and Taylor, R. (2004). Effect of exercise training on endothelium-derived nitric oxide function in humans. J. Physiol. 561(Pt 1), 1-25. doi: 10.1113/jphysiol.2004.068197

Green, D. J., Spence, A., Halliwill, J. R., Cable, N. T., and Thijssen, D. H. (2011). Exercise and vascular adaptation in asymptomatic humans. Exp. Physiol. 96, 57-70. doi: 10.1113/jphysiol.2004.068197

Griffiths, C., Wykes, V., Bellamy, T. C., and Garthwaite, J. (2003). A new and simple method for delivering clamped nitric oxide concentrations in the physiological range: application to activation of guanylyl cyclase-coupled nitric oxide receptors. Mol. Pharmacol. 64, 1349-1356. doi: 10.1124/mol.64.6.1349

Guo, F. H., De Raeve, H. R., Rice, T. W., Stuehr, D. J., Thunnissen, F. B., and Erzurum, S. C. (1995). Continuous nitric oxide synthesis by inducible nitric oxide synthase in normal human airway epithelium in vivo. Proc. Natl. Acad. Sci. U.S.A. 92, 7809-7813. doi: 10.1073/pnas.92.17.7809

Hambrecht, R., Adams, V., Erbs, S., Linke, A., Kränkel, N., Shu, Y., et al. (2003). Regular physical activity improves endothelial function in patients with coronary artery disease by increasing phosphorylation of endothelial nitric oxide synthase. Circulation 107, 3152-3158. doi: 10.1161/01.CIR.0000074229.93804.5C

Hambrecht, R., Wolf, A., Gielen, S., Linke, A., Hofer, J., Erbs, S., et al. (2000). Effect of exercise on coronary endothelial function in patients with coronary artery disease. N. Engl. J. Med. 342, 454-460. doi: 10.1056/NEJM200002173420702

Heaps, C. L., Mattox, M. L., Kelly, K. A., Meininger, C. J., and Parker, J. L. (2006). Exercise training increases basal tone in arterioles distal to chronic coronary occlusion. Am. J. Physiol. Heart Circ. Physiol. 290, H1128-H1135. doi: 10.1152/ajpheart.00973.2005

Ignarro, L. J., Buga, G. M., Wood, K. S., Byrns, R. E., and Chaudhuri, G. (1987). Endothelium-derived relaxing factor produced and released from artery and vein is nitric oxide. Proc. Natl. Acad. Sci. U.S.A. 84, 9265-9269. doi: 10.1073/pnas.84.24.9265

Ito, D., Ito, O., Cao, P., Mori, N., Suda, C., Muroya, Y., et al. (2013). Effects of exercise training on nitric oxide synthase in the kidney of spontaneously hypertensive rats. Clin. Exp. Pharmacol. Physiol. 40, 74-82. doi: 10.1111/14401681.12040

Iwamoto, J., Pendergast, D. R., Suzuki, H., and Krasney, J. A. (1994). Effect of graded exercise on nitric oxide in expired air in humans. Respir. Physiol. 97, 333-345. doi: 10.1016/0034-5687(94)90069-8

Johnson, L. R., Rush, J. W., Turk, J. R., Price, E. M., and Laughlin, M. H. (2001). Short-term exercise training increases ACh-induced relaxation and eNOS protein in porcine pulmonary arteries. J. Appl. Physiol. 90, 1102-1110. Available online at: http://jap.physiology.org/content/90/3/1102

Jones, A. M., Wilkerson, D. P., Koppo, K., Wilmshurst, S., and Campbell, I. T. (2003). Inhibition of nitric oxide synthase by L-NAME speeds phase II pulmonary.VO2 kinetics in the transition to moderate-intensity exercise in man. J. Physiol. 552(Pt 1), 265-272. doi: 10.1113/jphysiol.2003.045799

Kane, D. W., Tesauro, T., Koizumi, T., Gupta, R., and Newman, J. H. (1994). Exercise-induced pulmonary vasoconstriction during combined blockade of nitric oxide synthase and beta adrenergic receptors. J. Clin. Invest. 93, 677-683. doi: 10.1172/JCI117020

Kharitonov, S. A., Chung, K. F., Evans, D., O'Connor, B. J., and Barnes, P. J. (1996). Increased exhaled nitric oxide in asthma is mainly derived from the lower respiratory tract. Am. J. Respir. Crit. Care Med. 153(6 Pt 1), 1773-1780. doi: 10.1164/ajrccm.153.6.8665033

Kim-Shapiro, D. B., Gladwin, M. T., Patel, R. P., and Hogg, N. (2005). The reaction between nitrite and hemoglobin: the role of nitrite in hemoglobin-mediated hypoxic vasodilation. J. Inorg. Biochem. 99, 237-246. doi: 10.1016/j.jinorgbio.2004.10.034

Kingwell, B. A. (2000). Nitric oxide as a metabolic regulator during exercise: effects of training in health and disease. Clin. Exp. Pharmacol. Physiol. 27, 239-250. doi: 10.1046/j.1440-1681.2000.03232.x

Kippelen, P., Caillaud, C., Robert, E., Masmoudi, K., and Préfaut, C. (2002). Exhaled nitric oxide level during and after heavy exercise in athletes with exercise-induced hypoxaemia. Pflugers Arch. 444, 397-404. doi: 10.1007/s00424002-0816-y

Kleinbongard, P., Schulz, R., Rassaf, T., Lauer, T., Dejam, A., Jax, T., et al. (2006). Red blood cells express a functional endothelial nitric oxide synthase. Blood 107, 2943-2951. doi: 10.1182/blood-2005-10-3992

Koizumi, T., Gupta, R., Banerjee, M., and Newman, J. H. (1994). Changes in pulmonary vascular tone during exercise. Effects of nitric oxide (NO) synthase inhibition, L-arginine infusion, and NO inhalation. J. Clin. Invest. 94, 2275-2282. doi: 10.1172/JCI117590

Kosaka, H. (1999). Nitric oxide and hemoglobin interactions in the vasculature. Biochim. Biophys. Acta. 1411, 370-377. doi: 10.1016/S0005-2728(99)00026-2

Langberg, H., Bjørn, C., Boushel, R., Hellsten, Y., and Kjaer, M. (2002). Exerciseinduced increase in interstitial bradykinin and adenosine concentrations in skeletal muscle and peritendinous tissue in humans. J. Physiol. 542( $\mathrm{Pt} \mathrm{3}$ ), 977-983. doi: 10.1113/jphysiol.2002.018077

Larsen, B. T., Gutterman, D. D., Sato, A., Toyama, K., Campbell, W. B., Zeldin, D. C., et al. (2008). Hydrogen peroxide inhibits cytochrome p450 epoxygenases: interaction between two endothelium-derived hyperpolarizing factors. Circ. Res. 102, 59-67. doi: 10.1161/CIRCRESAHA.107.159129

Laughlin, M. H., Pollock, J. S., Amann, J. F., Hollis, M. L., Woodman, C. R., and Price, E. M. (2001). Training induces nonuniform increases in eNOS content along the coronary arterial tree. J. Appl. Physiol. (1985) 90, 501-510.

Laurindo, F. R. M., Pedro, M. D. A., Barbeiro, H. V., Pileggi, F., Carvalho, M. H., Augusto, O., et al. (1994). Vascular free radical release: ex vivo and in vivo 
evidence for a flow-dependent endothelial mechanism. Circ. Res. 74, 700-709. doi: 10.1161/01.RES.74.4.700

Liao, J. C., Hein, T. W., Vaughn, M. W., Huang, K. T., and Kuo, L. (1999). Intravascular flow decreases erythrocyte consumption of nitric oxide. Proc. Natl. Acad. Sci. U.S.A. 96, 8757-8761. doi: 10.1073/pnas.96.15.8757

Lührs, H., Papadopoulos, T., Schmidt, H. H., and Menzel, T. (2002). Type I nitric oxide synthase in the human lung is predominantly expressed in capillary endothelial cells. Respir. Physiol. 129, 367-374. doi: 10.1016/S00345687(01)00323-1

Lundberg, J. O., Weitzberg, E., Nordvall, S. L., Kuylenstierna, R., Lundberg, J. M., and Alving, K. (1994). Primarily nasal origin of exhaled nitric oxide and absence in Kartagener's syndrome. Eur. Respir. J. 7, 1501-1504. doi: 10.1183/09031936.94.07081501

Ma, Z. Y., and Zhao, Y. C. (2014). Effects of aerobic exercise training on antihypertension and expressions of VEGF, eNOS of skeletal muscle in spontaneous hypertensive rats. Zhongguo Ying Yong Sheng Li Xue Za Zhi. 30, 320-324.

Maarsingh, H., Zaagsma, J., and Meurs, H. (2009). Arginase: a key enzyme in the pathophysiology of allergic asthma opening novel therapeutic perspectives. Br. J. Pharmacol. 158, 652-664. doi: 10.1111/j.1476-5381.2009.0 0374.x

Maiorana, A., O'Driscoll, G., Taylor, R., and Green, D. (2003). Exercise and the nitric oxide vasodilator system. Sports Med. 33, 1013-1035. doi: 10.2165/00007256-200333140-00001

Mantione, K. J., Esch, T., and Stefano, G. B. (2007). Detection of nitric oxide in exhaled human breath: exercise and resting determinations. Med. Sci. Monit. 13, MT1-MT5. Available online at: http://www.medscimonit.com/download/index/idArt/475649

Maroun, M. J., Mehta, S., Turcotte, R., Cosio, M. G., and Hussain, S. N. (1995). Effects of physical conditioning on endogenous nitric oxide output during exercise. J. Appl. Physiol. 79, 1219-1225. Available online at: http://jap.physiology.org/content/79/4/1219

Marley, R., Patel, R. P., Orie, N., Ceaser, E., Darley-Usmar, V., and Moore, K. (2001). Formation of nanomolar concentrations of S-nitroso-albumin in human plasma by nitric oxide. Free Radic. Biol. Med. 31, 688-696. doi 10.1016/S0891-5849(01)00627-X

Michel, T., and Feron, O. (1997). Nitric oxide synthases: which, where, how, and why? J. Clin. Invest. 100, 2146-2152. doi: 10.1172/JCI1 19750

Miyauchi, T., Maeda, S., Iemitsu, M., Kobayashi, T., Kumagai, Y., Yamaguchi, I., et al. (2003). Exercise causes a tissue-specific change of NO production in the kidney and lung. J. Appl. Physiol. (1985) 94, 60-68.

Moien-Afshari, F., Ghosh, S., Elmi, S., Rahman, M. M., Sallam, N., Khazaei, M., et al. (2008). Exercise restores endothelial function independently of weight loss or hyperglycaemic status in $\mathrm{db} / \mathrm{db}$ mice. Diabetologia $51,1327-1337$. doi 10.1007/s00125-008-0996-x

Moncada, S. (1997). Nitric oxide in the vasculature: physiology and pathophysiology. Ann. N. Y. Acad. Sci. 811, 60-67. discussion: 67-69. doi: 10.1111/j.17496632.1997.tb51989.x

Morris, S. M. Jr., and Billiar, T. R. (1994). New insights into the regulation of inducible nitric oxide synthesis. Am. J. Physiol. 266(6 Pt 1), E829-E839.

Park, S., Shin, J., Hong, Y., Kim, S., Lee, S., Park, K., et al. (2012). Forced exercise enhances functional recovery after focal cerebral ischemia in spontaneously hypertensive rats. Brain Sci. 2, 483-503. doi: 10.3390/brainsci20 40483

Patel, H. J., Belvisi, M. G., Donnelly, L. E., Yacoub, M. H., Chung, K. F., and Mitchell, J. A. (1999). Constitutive expressions of type I NOS in human airway smooth muscle cells: evidence for an antiproliferative role. FASEB J. 13, $1810-1816$.

Pautz, A., Art, J., Hahn, S., Nowag, S., Voss, C., and Kleinert, H. (2010). Regulation of the expression of inducible nitric oxide synthase. Nitric Oxide 23, 75-93. doi 10.1016/j.niox.2010.04.007

Pechkovsky, D. V., Zissel, G., Stamme, C., Goldmann, T., Ari Jaffe, H., Einhaus, M., et al. (2002). Human alveolar epithelial cells induce nitric oxide synthase2 expression in alveolar macrophages. Eur. Respir. J. 19, 672-683. doi: 10.1183/09031936.02.00682001a

Pellegrin, M., Berthelot, A., Houdayer, C., Gaume, V., Deckert, V., and Laurant, P. (2007). New insights into the vascular mechanisms underlying the beneficial effect of swimming training on the endothelial vasodilator function in apolipoprotein E-deficient mice. Atherosclerosis 190, 35-42. doi: 10.1016/j.atherosclerosis.2006.02.001
Pellegrin, M., Miguet-Alfonsi, C., Berthelot, A., Mazzolai, L., and Laurant, P. (2011). Long-term swimming exercise does not modulate the Akt-dependent endothelial nitric oxide synthase phosphorylation in healthy mice. Can. J. Physiol. Pharmacol. 89, 72-76. doi: 10.1139/Y10-107

Persson, M. G., Wiklund, N. P., and Gustafsson, L. E. (1993). Endogenous nitric oxide in single exhalations and the change during exercise. Am. Rev. Respir. Dis. 148, 1210-1214. doi: 10.1164/ajrccm/148.5.1210

Rassaf, T., Preik, M., Kleinbongard, P., Lauer, T., Heiss, C., Strauer, B.-E., et al. Evidence for in vivo transport of bioactive nitric oxide in human plasma. (2002). J. Clin. Invest. 109, 1241-1248. doi: 10.1172/JCI0214995

Reitsma, S., Slaaf, D. W., Vink, H., van Zandvoort, M. A., and oude Egbrink, M. G. (2007). The endothelial glycocalyx: composition, functions, and visualization. Pflugers Arch. 454, 345-359. doi: 10.1007/s00424-007-0212-8

Ricciardolo, F. L. (2003). Multiple roles of nitric oxide in the airways. Thorax 58, 175-182. doi: 10.1136/thorax.58.2.175

Robinson, J. M., and Lancaster, J. R. (2005). Hemoglobin-mediated, hypoxiainduced vasodilation via nitric oxide - Mechanism(S) and physiologic versus pathophysiologic relevance. Amer. J. Respir. Cell Molec. Biol. 32, 257-261. doi: $10.1165 / \mathrm{rcmb} . \mathrm{F} 292$

Romanska, H. M., Polak, J. M., Coleman, R. A., James, R. S., Harmer, D. W., Allen, J. C., et al. (2002). iNOS gene upregulation is associated with the early proliferative response of human lung fibroblasts to cytokine stimulation. J. Pathol. 197, 372-379. doi: 10.1002/path.1116

Rush, J. W., Denniss, S. G., and Graham, D. A. (2005). Vascular nitric oxide and oxidative stress: determinants of endothelial adaptations to cardiovascular disease and to physical activity. Can. J. Appl. Physiol. 30, 442-474. doi 10.1139/h05-133

Rush, J. W. E., Turk, J. R., and Laughlin, M. H. (2003). Exercise training regulates SOD-1 and oxidative stress in porcine aortic endothelium. Am. J. Physiol. Heart Circ. Physiol. 284, H1378-H1387. doi: 10.1152/ajpheart.00190.2002

Sessa, W. C., Pritchard, K., Seyedi, N., Wang, J., and Hintze, T. H. (1994). Chronic exercise in dogs increases coronary vascular nitric oxide production and endothelial cell nitric oxide synthase gene expression. Circ. Res. 74, 349-353. doi: 10.1161/01.RES.74.2.349

Shaul, P. W., North, A. J., Wu, L. C., Wells, L. B., Brannon, T. S., Lau, K. S., et al. (1994). Endothelial nitric oxide synthase is expressed in cultured human bronchiolar epithelium. J. Clin. Invest. 94, 2231-2236. doi: 10.1172/JCI117585

Sheel, A. W., Road, J., and McKenzie, D. C. (1999). Exhaled nitric oxide during exercise. Sports Med. 28, 83-90. doi: 10.2165/00007256-199928020-00003

Shen, W., Zhang, X., Zhao, G., Wolin, M. S., Sessa, W., and Hintze, T. H. (1995). Nitric oxide production and NO synthase gene expression contribute to vascular regulation during exercise. Med. Sci. Sports Exerc. 27, 1125-1134. doi: 10.1249/00005768-199508000-00005

Shin, H. W., Rose-Gottron, C. M., Cooper, D. M., Hill, M., and George, S. C. (2003). Impact of high-intensity exercise on nitric oxide exchange in healthy adults. Med. Sci. Sports Exerc. 35, 995-1003. doi: 10.1249/01.MSS.0000072247.46963.CD

Shin, H. W., Rose-Gottron, C. M., Perez, F., Cooper, D. M., Wilson, A. F., and George, S. C. (2001). Flow-independent nitric oxide exchange parameters in healthy adults. J. Appl. Physiol. (1985) 91, 2173-2181. Available online at: http://jap.physiology.org/content/jap/91/5/2173.full.pdf

Shin, H. W., Rose-Gottron, C. M., Sufi, R. S., Perez, F., Cooper, D. M., Wilson, A. F., et al. (2002). Flow-independent nitric oxide exchange parameters in cystic fibrosis. Am. J. Respir. Crit. Care. Med. 165, 349-357. doi: 10.1164/ajr$\mathrm{ccm} \cdot 165.3 .2105098$

Silkoff, P. E., McClean, P. A., Slutsky, A. S., Furlott, H. G., Hoffstein, E., Wakita, S., et al. (1997). Marked flow-dependence of exhaled nitric oxide using a new technique to exclude nasal nitric oxide. Am. J. Respir. Crit. Care Med. 155, 260-267. doi: 10.1164/ajrccm.155.1.9001322

Sindler, A. L., Delp, M. D., Reyes, R., Wu, G., and Muller-Delp, J. M. (2009). Effects of ageing and exercise training on eNOS uncoupling in skeletal muscle resistance arterioles. J. Physiol. 587(Pt 15), 3885-3897. doi: 10.1113/jphysiol.2009.172221

Spriestersbach, R., Grimminger, F., Weissmann, N., Walmrath, D., and Seeger W. (1995). On-line measurement of nitric oxide generation in buffer-perfused rabbit lungs. J. Appl. Physiol. (1985) 78, 1502-1508.

Stamler, J. S., Simon, D. I., Osborne, J. A., Mullins, M. E., Jaraki, O., Michel, T., et al. (1992a). S-nitrosylation of proteins with nitric oxide: synthesis and characterization of biologically active compounds. Proc. Natl. Acad. Sci. USA. 89, 444-448. doi: 10.1073/pnas.89.1.444 
Stamler, J. S., Jaraki, O., Osborne, J., Simon, D. I., Keaney, J., et al. (1992b). Nitric oxide circulates in mammalian plasma primarily as an S-nitroso adduct of serum albumin. Proc. Natl. Acad. Sci. U.S.A. 89, 7674-7677. doi: 10.1073/pnas.89.16.7674

St Croix, C. M., Wetter, T. J., Pegelow, D. F., Meyer, K. C., and Dempsey, J. A. (1999). Assessment of nitric oxide formation during exercise. Am. J. Respir. Crit. Care Med. 159(4 Pt 1), 1125-1133. doi: 10.1164/ajrccm.159.4.9806144

Suman, O. E., and Beck, K. C. (2002). Role of airway endogenous nitric oxide on lung function during and after exercise in mild asthma. J. Appl. Physiol. (1985) 93, 1932-1938. doi: 10.1152/japplphysiol.00503.2002

Sumino, H., Sato, K., Sakamaki, T., Masuda, H., Nakamura, T., Kanda, T., et al. (1998). Decreased basal production of nitric oxide in patients with heart disease. Chest 113, 317-322. doi: 10.1378/chest.113.2.317

Tatchum-Talom, R., Schulz, R., McNeill, J. R., and Khadour, F. H. (2000). Upregulation of neuronal nitric oxide synthase in skeletal muscle by swim training. Am. J. Physiol. Heart Circ. Physiol. 279, H1757-H1766. Available online at: http://ajpheart.physiology.org/content/ajpheart/279/4/H1757.full.pdf

Taylor-Robinson, A. W. (2000). The sequestration hypothesis: an explanation for the sensitivity of malaria parasites to nitric oxide-mediated immune effector function in vivo. Med. Hypotheses 54, 638-641. doi: 10.1054/mehy. 1999.0914

Thengchaisri, N., Shipley, R., Ren, Y., Parker, J., and Kuo, L. (2007). Exercise training restores coronary arteriolar dilation to NOS activation distal to coronary artery occlusion: role of hydrogen peroxide. Arterioscler. Thromb. Vasc. Biol. 27, 791-798. doi: 10.1161/01.ATV.0000258416.47953.9a

Tsoukias, N. M., and George, S. C. (1998). A two-compartment model of pulmonary nitric oxide exchange dynamics. J. Appl. Physiol. (1985) 85, 653-666.

Tsoukias, N. M., Shin, H. W., Wilson, A. F., and George, S. C. (2001). A singlebreath technique with variable flow rate to characterize nitric oxide exchange dynamics in the lungs. J. Appl. Physiol. (1985) 91, 477-487.

Tsoukias, N. M., Tannous, Z., Wilson, A. F., and George, S. C. (1998). Singleexhalation profiles of $\mathrm{NO}$ and $\mathrm{CO} 2$ in humans: effect of dynamically changing flow rate. J. Appl. Physiol. (1985) 85, 642-652.

Tzao, C., Nickerson, P. A., Russell, J. A., Noble, B. K., and Steinhorn, R. H. (2000). Heterogeneous distribution of type I nitric oxide synthase in pulmonary vasculature of ovine fetus. Histochem. Cell Biol. 114, 421-430. doi: 10.1007/s00418 0000205

Vallance, P., and Chan, N. (2001). Endothelial function and nitric oxide: clinical relevance. Heart. 85, 342-350. doi: 10.1136/heart.85.3.342

Vaughn, M. W., Huang, K. T., Kuo, L., and Liao, J. C. (2000). Erythrocytes possess an intrinsic barrier to nitric oxide consumption. J. Biol. Chem. 275, 2342-2348. doi: $10.1074 /$ jbc. 275.4 .2342

Veeramachaneni, N. K., Harken, A. H., and Cairns, C. B. (1999). Clinical implications of hemoglobin as a nitric oxide carrier. Arch. Surg. 134, 434-437. doi: 10.1001/archsurg.134.4.434

Verges, S., Flore, P., Favre-Juvin, A., Lévy, P., and Wuyam, B. (2005). Exhaled nitric oxide during normoxic and hypoxic exercise in endurance athletes. Acta Physiol. Scand. 185, 123-131. doi: 10.1111/j.1365-201X.2005.01475.x
Verges, S., Tonini, J., Flore, P., Favre-Juvin, A., Lévy, P., and Wuyam, B. (2006). Exhaled nitric oxide in single and repetitive prolonged exercise. J. Sports Sci. 24, 1157-1163. doi: 10.1080/02640410500457364

Wan, J., Ristenpart, W. D., and Stone, H. A. (2008). Dynamics of shear-induced ATP release from red blood cells. Proc. Natl. Acad. Sci. U.S.A. 105, 16432-16437. doi: 10.1073/pnas.0805779105

Ward, J. K., Barnes, P. J., Tadjkarimi, S., Yacoub, M. H., and Belvisi, M. G. (1995). Evidence for the involvement of cGMP in neural bronchodilator responses in humal trachea. J. Physiol. 483(Pt 2), 525-536.

Whittle, B. J. (1995). Nitric oxide in physiology and pathology. Histochem. J. 27, 727-737. doi: 10.1007/BF02388298

Whyte, J. J., and Laughlin, M. H. (2010). The effects of acute and chronic exercise on the vasculature. Acta. Physiol. (Oxf). 199, 441-450. doi: 10.1111/j.17481716.2010.02127.x

Xie, W., Parker, J. L., and Heaps, C. L. (2012). Effect of exercise training on nitric oxide and superoxide/H2O 2 signaling pathways in collateral-dependent porcine coronary arterioles. J. Appl. Physiol. (1985) 112, 1546-1555. doi: 10.1152/ japplphysiol.01248.2011

Xue, C., and Johns, R. A. (1996). Upregulation of nitric oxide synthase correlates temporally with onset of pulmonary vascular remodeling in the hypoxic rat. Hypertension 28, 743-753. doi: 10.1161/01.HYP.28.5.743

Zaros, P. R., Pires, C. E., Bacci, M. Jr., Moraes, C., and Zanesco, A. (2009). Effect of 6-months of physical exercise on the nitrate/nitrite levels in hypertensive postmenopausal women. BMC Womens. Health 9:17. doi: 10.1186/1472-6874-9-17

Zhan, X., Li, D., and Johns, R. A. (2003). Expression of endothelial nitric oxide synthase in ciliated epithelia of rats. J. Histochem. Cytochem. 51, 81-87. doi: 10.1177/002215540305100110

Zhang, Q. J., McMillin, S. L., Tanner, J. M., Palionyte, M., Abel, E. D., and Symons, J. D. (2009). Endothelial nitric oxide synthase phosphorylation in treadmill-running mice: role of vascular signalling kinases. J. Physiol. 587( $\mathrm{Pt}$ 15), 3911-3920. doi: 10.1113/jphysiol.2009.172916

Conflict of Interest Statement: The authors declare that the research was conducted in the absence of any commercial or financial relationships that could be construed as a potential conflict of interest.

Received: 29 September 2014; accepted: 08 December 2014; published online: 07 January 2015.

Citation: Nosarev AV, Smagliy LV, Anfinogenova Y, Popov SV and Kapilevich LV (2015) Exercise and NO production: relevance and implications in the cardiopulmonary system. Front. Cell Dev. Biol. 2:73. doi: 10.3389/fcell.2014.00073

This article was submitted to Mitochondrial Research, a section of the journal Frontiers in Cell and Developmental Biology.

Copyright (C) 2015 Nosarev, Smagliy, Anfinogenova, Popov and Kapilevich. This is an open-access article distributed under the terms of the Creative Commons Attribution License (CC BY). The use, distribution or reproduction in other forums is permitted, provided the original author(s) or licensor are credited and that the original publication in this journal is cited, in accordance with accepted academic practice. No use, distribution or reproduction is permitted which does not comply with these terms. 